\title{
Structure-Activity Relationship of Oleanane Disaccharides Isolated from Akebia quinata versus Cytotoxicity against Cancer Cells and NO Inhibition
}

\author{
Hyun-Ju Jung, ${ }^{a}$ Chong Ock LeE, ${ }^{b}$ Kyung-Tae LeE, ${ }^{c}$ Jongwon ChoI, ${ }^{d}$ and Hee-Juhn PARK $*, a$ \\ ${ }^{a}$ Division of Applied Plant Sciences, Sangji University; Wonju 220-802, Korea: ${ }^{b}$ Pharmaceutical Screening Center, Korea \\ Research Institute of Chemical Technology; Daejeon 305-606, Korea: ${ }^{c}$ College of Pharmacy, Kyung-Hee University; \\ Seoul, 130-701 Korea: and ${ }^{d}$ College of Pharmacy, Kyungsung University; Pusan 608-736, Korea. \\ Received October 2, 2003; accepted December 11, 2003
}

In order to further determine the nature of structure-activity relationship on the cytotoxicities of saponins with $1 \rightarrow 2$ and $1 \rightarrow 3$ linkages of disaccharides, we isolated guaianin $N$, collinsonidin, kalopanaxsaponin $A$ and hederoside $\mathrm{D}_{2}$ as disaccharides, and patrinia glycoside B-II as a trisaccharide, from the $n$-BuOH extract of $A$ kebia quinata (Lardizabalaceae). Complete acid hydrolysis of the extract afforded oleanolic acid (1) and hederagenin (2). By sulforhodamine B (SRB) assay, kalopanaxsaponin A containing an $\alpha$-L-rhap-(1 $\rightarrow 2)-\alpha$-L-arap moiety exhibited distinctly higher cytotoxicity $\left(\mathrm{IC}_{50} 1.8-2.7 \mu \mathrm{g} / \mathrm{ml}\right)$ against all of the tested cell lines than the other saponins $\left(\mathrm{IC}_{50}, 4-8 \mu \mathrm{g} / \mathrm{ml}\right)$. These results suggest that the $\alpha$-L-rhap-(1 $\left.\rightarrow 2\right)-\alpha$-L-arap moiety has a unique structural significance in terms of its cell biochemistry, compared to those oleanane glycosides with other sugar linkages. On the other hand, kalopanaxsaponin A exhibited a significant inhibitory effect on nitric oxide production by lipopolysaccharide (LPS)-activated macrophage 264.7, whereas other saponins had weaker activities.

Key words oleanane disaccharide; kalopanaxsaponin A; cytotoxicity; Akebia quinata; structure-activity relationship (SAR)

Akebia quinata DeCAISENE (Lardizabalaceae) is a creeping woody vine which is widely distributed in East Asia. Its dried stems have been traditionally used as an antiphlogistic, a diuretic and an analgesic. ${ }^{1)}$ This plant contains many saponins, which are glycosides of oleanolic acid, hederagenin or norarjunolic acid. ${ }^{2,3)}$

Quetin-Leclercq et al. $^{4)}$ reported that hederagenin monodesmosides are toxic to tumor cell lines whereas bisdesmosides are inactive in the same cell lines. We previously reported that the disaccharides of hederagenin 3-O-glycosides isolated from Kalopanax pictus NAKAI play an important role in this cytotoxic action, but that hederagenin 3-O-arabinoside ( $\delta$-hederin), a monosaccharide, has no cytotoxic effect. ${ }^{5,6)}$ In addition, though hederagenin 3-O-arabinoside and hederagenin 3-O-[glucosyl $(1 \rightarrow 4)$-arabinoside] are not cytotoxic, ${ }^{7)}$ echinocystic acid 3-O-glucuronic acid has mild cytotoxicity. ${ }^{8)}$ Saponins may be hydrolyzed in the gastrointestinal tract by human intestinal bacteria when orally administered. ${ }^{9,10)}$ In addition, these reports suggest that the kinds or type of linkage between the sugar and the saponin is of pivotal importance in terms of cytotoxicity. The cytotoxicities of the oleanane disaccharides with $1 \rightarrow 2$ or $1 \rightarrow 4$ linkage are known. However, those of hederagenin disaccharides with $1 \rightarrow 3$ linkage have not been compared with saponins which have other types of linkage. Elucidation of the cytotoxicities of these saponin types should enable us to better understand biological saponins, since the first sugar arabinose, a pentopyranose, can only attach sugars at the OHs 1, 2, 3 and 4 positions.

Therefore, we attempted to establish the full structure-cytotoxicity relationship of hederagenin 3-O-disaccharides by isolating saponins with $1 \rightarrow 3$ sugar linkages from $A$. quinata. We also assayed NO inhibitory activity in lipopolysaccharide (LPS)-induced macrophage 264.7 cells, since saponins often have anti-inflammatory effects.

\section{MATERIALS AND METHODS}

General Experimental Procedures Melting points were determined on a Yanagimoto micromelting point apparatus. Optical rotations were measured on a JASCO DIP-360 digital polarimeter at $25^{\circ} \mathrm{C}$. IR spectra were recorded on a Hitachi 260-01 spectrometer from KBr disks. EI-mass spectra (ionization voltage, $70 \mathrm{eV}$ ) were measured using a Finnigan Mat TSQ-700 mass spectrometer. ${ }^{1} \mathrm{H}$ - and ${ }^{13} \mathrm{C}$-NMR spectra were recorded using a Brucker AMX-500 spectrometer, with TMS as an internal standard.

Plant Material The creeping stems of $A$. quinata were collected in September 2001, on Chiak Mountain, Kangwon Province, Korea, and identified by Prof. G. T. Kim (Division of Applied Plant Sciences, Sangji University, Wonju, Korea). A voucher specimen (\# natchem-22) has been deposited at the herbarium of Applied Plant Sciences, Sangji University, Wonju, Korea.

Extraction and Fractionation The air-dried creeping stems $(4 \mathrm{~kg})$ of $A$. quinata were cut and extracted three times with $\mathrm{MeOH}$ under reflux at $40^{\circ} \mathrm{C}$. The obtained $\mathrm{MeOH}$ solution was evaporated under reduced pressure to give a viscous mass $(400 \mathrm{~g})$, which was then partitioned in distilled water (11) and $\mathrm{CHCl}_{3}$ (2.11) solution, and then further extracted with $\mathrm{BuOH}(2.11)$ solution.

Acid Hydrolysis and Isolation of the BuOH-Soluble Fraction The $\mathrm{BuOH}$-soluble fraction (15g) was hydrolyzed in $5 \%-\mathrm{HCl} \mathrm{MeOH} / \mathrm{H}_{2} \mathrm{O}(=2: 8,200 \mathrm{ml})$ under reflux for $4 \mathrm{~h}$. After cooling, the reaction mixture was neutralized with diluted $\mathrm{NaOH}$ solution and extracted with ethyl acetate (EtOAc, $800 \mathrm{ml})$. The EtOAC soluble fraction $(5 \mathrm{~g})$ was washed with distilled water and chromatographed on a silica gel (480 - 580 mesh, Merck, Art 7734, Germany) column using $\mathrm{CHCl}_{3}-\mathrm{MeOH}-\mathrm{H}_{2} \mathrm{O}(90: 7: 1$, lower phase, 11$)$, to produce four sub-fractions (AqH-1-4). Repeated column chromatography of $\mathrm{AqH} 2(1 \mathrm{~g}, 190-280 \mathrm{ml})$ and $3(800 \mathrm{mg}$, $300-370 \mathrm{ml}$ ) under the same condition (silica gel, 
$\mathrm{CHCl}_{3}-\mathrm{MeOH}-\mathrm{H}_{2} \mathrm{O}=90: 7: 1$, lower phase, $500 \mathrm{ml}$ ), followed by recrystallization from $\mathrm{MeOH}$, afforded $1(12 \mathrm{mg}$, $160-230 \mathrm{ml})$ and $2(10 \mathrm{mg}, 280-350 \mathrm{ml})$, respectively.

1: White powder $(12 \mathrm{mg}),[\alpha]_{\mathrm{D}}^{21}+64.6^{\circ}\left(c=0.3, \mathrm{CHCl}_{3}\right) .{ }^{11)}$ 2: White powder $(10 \mathrm{mg}),[\alpha]_{\mathrm{D}}^{21}+64.5^{\circ}\left(c=0.6, \mathrm{CHCl}_{3}\right) .{ }^{11)}$

Isolation of Compounds 3-7 The $\mathrm{BuOH}$-soluble fraction $(30 \mathrm{~g})$ was loaded onto a silica gel column, and eluted with $\mathrm{CHCl}_{3}-\mathrm{MeOH}-\mathrm{H}_{2} \mathrm{O}(7: 3: 1$, lower phase, 31$)$ to give six fractions, which were labeled AqFr1-6. Silica gel column chromatography of AqFr2 (1 g, 600-900 ml) using $\mathrm{CHCl}_{3}-\mathrm{MeOH}_{-} \mathrm{H}_{2} \mathrm{O}(75: 25: 10$, lower phase, 1.51$)$ yielded five sub-fractions (AqFr2-1-5). Of these fractions, AqFr2-3 (400 mg, 750-900 ml) was chromatographed by reverse phase ODS (MeOH: $\mathrm{H}_{2} \mathrm{O}=5: 5,6: 4,7: 3$ and $\left.8: 2,400 \mathrm{ml}\right)$ and yielded $3(15 \mathrm{mg}, 200-350 \mathrm{ml})$. Combined AqFr3 (2 g, $900-1700 \mathrm{ml})$ and AqFr2-4 (200 mg, 900-1100 ml) were subjected to column chromatography on RP-18 using $\mathrm{MeOH}: \mathrm{H}_{2} \mathrm{O}(500 \mathrm{ml})=7: 3$ and $8: 2$, respectively, to yield four sub-fractions (AqFr3-1-4). Column chromatography of AqFr3-2 (400 mg, 200-280 ml) by reverse phase ODS using $\mathrm{MeOH}: \mathrm{H}_{2} \mathrm{O} \quad(300 \mathrm{ml})=7: 3$, yielded $4(15 \mathrm{mg}, 150-$ $200 \mathrm{ml}$ ), and that of AqFr3-3 (300 mg, 280-330 ml) by silica gel using $\mathrm{CHCl}_{3}: \mathrm{MeOH}: \mathrm{H}_{2} \mathrm{O}=78: 22: 10(500 \mathrm{ml})$ afforded $5(10 \mathrm{mg}, 230-310 \mathrm{ml})$. Constituents $5(20 \mathrm{mg})$ and 6 $(11 \mathrm{mg})$ of AqFr4 (3 g, 2500-3500 ml) were purified by repeated step-gradient column chromatography over silica gel $\left(\mathrm{CHCl}_{3}: \mathrm{MeOH}: \mathrm{H}_{2} \mathrm{O}=95: 5: 10 \rightarrow 65: 35: 10,500 \mathrm{ml}\right.$, retention volumn 6: $1700-2400 \mathrm{ml}, \mathbf{5}: 1000-1300 \mathrm{ml})$, followed by RP-18 column chromatography $\left(\mathrm{MeOH}: \mathrm{H}_{2} \mathrm{O}=7: 3\right.$, $500 \mathrm{ml}$, retention volumn 6: $70-120 \mathrm{ml}, 5$ : $100-180 \mathrm{ml})$ and finally were recrystallized from MeOH. AqFr5 ( $1 \mathrm{~g}$, $2400-2700 \mathrm{ml}$ ) was purified on silica gel and RP-18 columns, eluted with $\mathrm{CHCl}_{3}-\mathrm{MeOH}(8: 2,300 \mathrm{ml})$ and $\mathrm{MeOH}: \mathrm{H}_{2} \mathrm{O}(7: 3,300 \mathrm{ml})$, respectively, which afforded 7 ( $15 \mathrm{mg}$, retention volumn: $150-220 \mathrm{ml}$ and $300-450 \mathrm{ml}$ ). Compound $\mathbf{8}$ was isolated from the $n$ - $\mathrm{BuOH}$ fraction of Kalopanax pictus, the overall procedure was described in the previous paper. ${ }^{6}$

3: White powder $(15 \mathrm{mg}),[\alpha]_{\mathrm{D}}^{21}+140^{\circ}(c=0.3, \mathrm{MeOH}){ }^{12)}$

4: White powder $(15 \mathrm{mg}),[\alpha]_{\mathrm{D}}^{21}+55.6^{\circ}(c=0.4, \mathrm{MeOH}){ }^{12)}$

5: White powder $(30 \mathrm{mg}),[\alpha]_{\mathrm{D}}^{21}+15^{\circ}(c=1.4 \mathrm{in} \mathrm{MeOH}){ }^{12)}$

6: White powder $(11 \mathrm{mg}),[\alpha]_{\mathrm{D}}^{21}+40^{\circ}(c=1.7, \mathrm{MeOH}){ }^{13)}$

7: White powder $(15 \mathrm{mg}),[\alpha]_{\mathrm{D}}^{21}+2.9^{\circ}(c=0.3, \mathrm{MeOH}){ }^{12)}$

8: White powder $(20 \mathrm{mg}),[\alpha]_{\mathrm{D}}^{21}+11.0^{\circ}(c=5.4, \mathrm{MeOH}){ }^{12)}$

Cytotoxicity SRB (sulforhodamine B) assay, which was developed to measure the protein content of cell cultures, was used to measure the cytotoxic effect of the isolated compounds on tumor cells. The rapidly growing cells, A549 (human lung tumor), SK-OV-3 (human ovarian tumor), SKMEL-2 (human melanoma), XF498 (human brain tumor) and HCT15 (human colon tumor) were harvested, counted, and inoculated at the appropriate concentrations $\left(1-2 \times 10^{4}\right.$ cells/well) into 96 well microtiter plates. After incubation for $24 \mathrm{~h}$, the compounds $(\mathbf{1}-\mathbf{8})$ dissolved in culture medium were applied to the culture wells in triplicate and then incubated for $48 \mathrm{~h}$ at $37^{\circ} \mathrm{C}$ under a $5 \% \mathrm{CO}_{2}$ atmosphere. The cultures were fixed with cold TCA and stained with $0.4 \%$ SRB dissolved in $1 \%$ acetic acid. After solubilizing the bound dye with $10 \mathrm{~mm}$ of unbuffered tris base in a gyratory shaker, the absorbance was measured at $520 \mathrm{~nm}$ with a microplate reader. The $50 \%$ inhibitory concentration $\left(\mathrm{ED}_{50}\right)$ was defined as the concentration that reduced the absorbance of the untreated wells by $50 \%$ of the control in the SRB assay. ${ }^{14)}$

Cell Culture and Sample Treatment The RAW 264.7 murine macrophage cell line was obtained from the Korea Cell Line Bank (Seoul, Korea). These cells were grown at $37^{\circ} \mathrm{C}$ in DMEM medium supplemented with $10 \% \mathrm{FBS}$, penicillin (100 units $/ \mathrm{ml})$ and streptomycin sulfate (100 units $/ \mathrm{ml}$ ) in a humidified atmosphere of $5 \% \mathrm{CO}_{2}$. The cells were then incubated with hederagenin monodesmosides at increasing concentrations $(5-50 \mu \mathrm{M})$ and stimulated with LPS $1 \mu \mathrm{g} / \mathrm{ml}$ for $24 \mathrm{~h}$.

MTT Assay for Cell Viability Cytotoxicity studies were performed in a well plate. ${ }^{15)}$ RAW 264.7 cells were mechanically scraped and plated at $2 \times 10^{5} /$ well in 96 -well plate containing $100 \mu \mathrm{l}$ of DMEM containing $10 \%$ FBS, and then incubated overnight. Isolated compounds $(\mathbf{1}-\mathbf{8})$ were dissolved in dimethylsulfoxide (DMSO, the DMSO concentration in all assays did not exceed $0.1 \%$ ). Twenty-four hours after seeding, $100 \mu \mathrm{l}$ of new medium or a mixture with a hederagenin monodesmoside was added, and the plates were incubated for another $24 \mathrm{~h}$. Cells were washed once before adding $50 \mu \mathrm{l}$ of FBS-free medium containing $5 \mathrm{mg} / \mathrm{ml}$ of MTT. After $4 \mathrm{~h}$ of incubation at $37^{\circ} \mathrm{C}$, the medium was discarded and formazan blue, which formed in the cells, was dissolved in $50 \mu \mathrm{l}$ of DMSO. Optical density was measured at $540 \mathrm{~nm}$. The concentration required to reduce the absorbance by $50 \%\left(\mathrm{IC}_{50}\right)$ versus the control was determined.

Nitrite Assay Nitrite accumulation, an indicator of NO synthesis, was measured in the culture medium by using the Griess reaction. ${ }^{16)}$ Briefly, $100 \mu$ l of cell culture medium was mixed with $100 \mu \mathrm{l}$ of Griess reagent [equal volumes of $1 \%$ $(\mathrm{w} / \mathrm{v})$ sulfanilamide in $5 \%(\mathrm{v} / \mathrm{v})$ phosphoric acid and $0.1 \%$ $(\mathrm{w} / \mathrm{v})$ naphthylethylenediamine- $\mathrm{HCl}$ ] and incubated at room temperature for $10 \mathrm{~min}$. The absorbance at $550 \mathrm{~nm}$ was then measured in a microplate reader. Fresh culture medium was used as the blank in all experiments. The amount of nitrite in the samples was calculated using a sodium nitrite standard

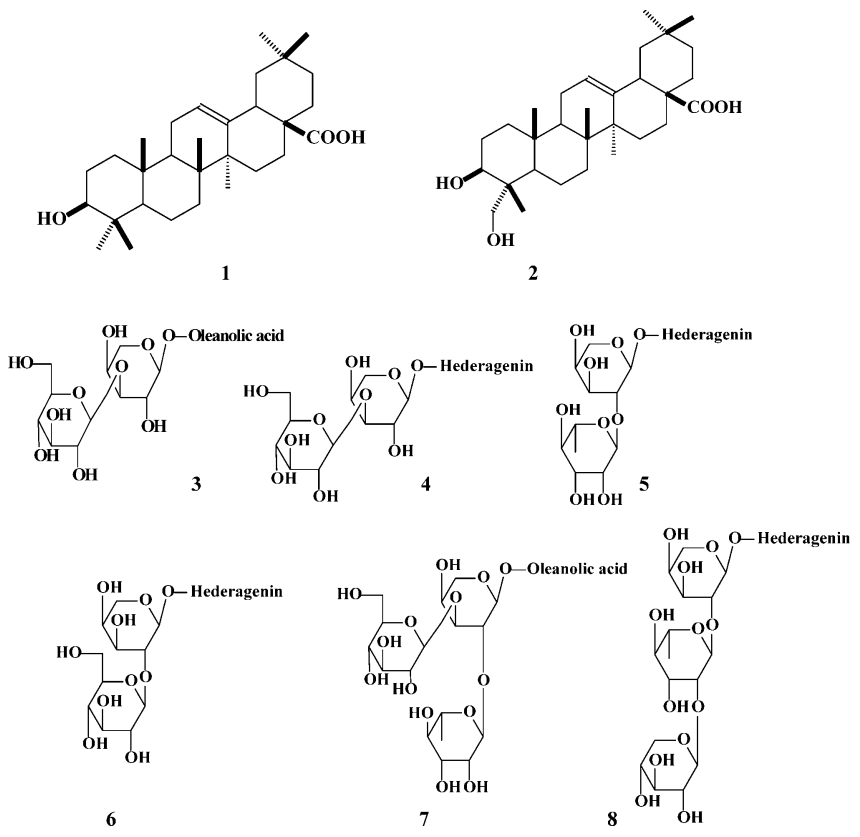

Fig. 1. Structures of Triterpenes $(\mathbf{1}, \mathbf{2})$ and Triterpenoid Saponins $(\mathbf{3}-\mathbf{7})$ Isolated from A. quinata and a Reference Compound (8) 
curve freshly prepared in culture medium.

\section{RESULTS}

Although the cytotoxic effect of the $\mathrm{MeOH}$ extract of $A$. quinata was found to be slight, $\left(>\mathrm{IC}_{50} 60 \mu \mathrm{g} / \mathrm{ml}\right)$, the $n$ $\mathrm{BuOH}$ fraction, which is often referred to as the saponin fraction, showed potent activity with an $\mathrm{IC}_{50}$ exceeding 17 $23 \mu \mathrm{g} / \mathrm{ml}$ against the cancer cell lines, except XF498 $\left(\mathrm{IC}_{50}\right.$ $98 \mu \mathrm{g} / \mathrm{ml})$. By repeated column chromatography of the saponin fraction, we isolated guaianin $\mathrm{N}$ (oleanolic acid 3$O$-[ $\beta$-D-glucopyranosyl- $(1 \rightarrow 3)-\alpha$-L-arabinopyranoside $], \quad 3)$, collinsonidin (hederagenin 3- $O$-[ $\beta$-D-glucopyranosyl- $(1 \rightarrow 3)$ $\alpha$-L-arabinopyranoside], 4), kalopanaxsaponin A (hederagenin 3-O-[ $\alpha$-L-rhamnopyranosyl- $(1 \rightarrow 2)-\alpha$-L-arabinopyranoside], 5), hederoside $\mathrm{D}_{2}$ (caulosaponin $\mathrm{B}$, hederagenin 3- $O$-[ $\beta$-D-glucopyranosyl- $(1 \rightarrow 2)-\alpha$-L-arabinopyranoside $], 6)$ and patrinia glycoside B-1l (oleanolic acid 3-O-\{ $\alpha-\mathrm{L}-$ rhamnopyranosyl- $(1 \rightarrow 2)$ - $[\beta$-D-glucopyranosyl- $(1 \rightarrow 3)]-\alpha$-Larabinopyranoside $\}, 7)$. Oleanolic acid (1) and hederagenin (2) were further isolated after the acid hydrolysis of the $n$ $\mathrm{BuOH}$ fraction. All isolated compounds were identified on the basis of mp, $[\alpha]_{\mathrm{D}}$, and by ${ }^{1} \mathrm{H}$ - and ${ }^{13} \mathrm{C}-\mathrm{NMR} .{ }^{11-13)}$

We tested the cytotoxicity of the isolated compounds by SRB assay and further examined their inhibitory effect on the formation of NO in LPS-activated macrophage 264.7 cells by using a nitrite assay. The cytotoxic effect of the compounds against macrophage cells was also measured to determine whether the effect was due to the inhibition of NO formation or to cell death. To obtain more information on the effects of saponins, we included a standard sample of kalopanaxsapo$\operatorname{nin}$ I $(8$, hederagenin 3- $O$-[ $\beta$-D-xylopyranosyl- $(1 \rightarrow 2)-\alpha$-Lrhamnopyranosyl-( $1 \rightarrow 2)-\alpha$-L-arabinopyranoside]) in the assays.

The isolated saponins exhibited potent cytotoxicities of more than $\mathrm{IC}_{50} 1-8 \mu \mathrm{g} / \mathrm{ml}$ against all of the tested cell lines: A549, SK-OV-3, SK-MEL-2, XF498 and HCT15. Moreover, they exhibited greater cytotoxic effects on SK-OV-3 and HCT15 than on other cell lines. Oleanolic acid (1) and hederagenin (2) belong to the most typical sapogenin in oleananetype triterpene saponins. Hederagenin $\left(\mathrm{IC}_{50} 15-23 \mu \mathrm{g} / \mathrm{ml}\right)$ was more potent by assay than oleanolic acid $\left(\mathrm{IC}_{50} 62-\right.$ $99 \mu \mathrm{g} / \mathrm{ml}$ ), suggesting that the presence of $23-\mathrm{OH}$ enhances the activity of oleanolic acid. ${ }^{17)}$ However, the cytotoxic effects of saponin $3\left(\mathrm{IC}_{50} 4.1-7.5 \mu \mathrm{g} / \mathrm{ml}\right)$ with oleanolic acid and $4\left(\mathrm{IC}_{50} 5.1-7.4 \mu \mathrm{g} / \mathrm{ml}\right)$ with hederagenin were very similar, which suggests that their cytotoxic effects are attributable not to sapogenins but to sugars. The results shown in Table 2 suggest that the triterpene saponin moiety does not determine the cytotoxicity, but that the oligosaccharides at C3 of the sapogenin do have an effect.

The cytotoxic effects of compounds 4 and $\mathbf{6}$ were very similar (4: $\mathrm{IC}_{50} 5.1-7.4 \mu \mathrm{g} / \mathrm{ml} ; 6: \mathrm{IC}_{50} \quad 6.3-8.4 \mu \mathrm{g} / \mathrm{ml}$ ). These compounds have the same molecular weight, but a different linkage position between the two sugars. The former has $1 \rightarrow 3$ linkage and the latter $1 \rightarrow 2$ linkage. This result indicates that the linkages $1 \rightarrow 2$ or $1 \rightarrow 3$ are not crucial for cytotoxicity. The cytotoxic effects of $\mathbf{5}$ and $\mathbf{6}$ were as follows: $\mathrm{IC}_{50} 1.9-2.7 \mu \mathrm{g} / \mathrm{ml}$ (5) and $\mathrm{IC}_{50} 6.3-8.4 \mu \mathrm{g} / \mathrm{ml}$ (6). Compound 5 contains a second sugar, rhamnose, but 6 has glucose in this position. Both compounds have the $1 \rightarrow 2$ linkage
Table 1. Cytotoxic Effects of Each Extract Obtained from A. quinata on Tumor Cell Growth

\begin{tabular}{lccccc}
\hline \hline \multirow{2}{*}{ Extract } & \multicolumn{5}{c}{$\mathrm{IC}_{50}(\mu \mathrm{g} / \mathrm{ml})^{a)}$} \\
\cline { 2 - 6 } & $\mathrm{A} 549$ & SK-OV-3 & SK-MEL-2 & XF498 & HCT15 \\
\hline MeOH ext. & $>100^{b)}$ & 65 & 63 & $>100$ & 84 \\
CHCl ext. $_{\text {BuOH ext. }}^{20}$ & 22 & 18 & 16 & 41 & 20 \\
Doxorubicin & 0.07 & 0.2 & 20 & 98 & 23 \\
& & & 0.03 & 0.3 & 0.2 \\
\hline
\end{tabular}

a) $\mathrm{IC}_{50}$ is defined as the concentration which resulted in a $50 \%$ decrease in cell number. b) The values represent the means of three independent experiments.

Table 2. Cytotoxic Effects of the Compounds $(\mathbf{1}-\mathbf{8})$ on Tumor Cell Growth

\begin{tabular}{cccccc}
\hline \hline \multirow{2}{*}{ Constituents } & \multicolumn{5}{c}{$\mathrm{IC}_{50}(\mu \mathrm{g} / \mathrm{ml})^{a)}$} \\
\cline { 2 - 6 } & $\mathrm{A549}$ & SK-OV-3 & SK-MEL-2 & XF498 & HCT15 \\
\hline $\mathbf{1}$ & $62^{b)}$ & 63 & 77 & 99 & 86 \\
$\mathbf{2}$ & 15 & 17 & 22 & 23 & 18 \\
$\mathbf{3}$ & 7.5 & 4.1 & 6.4 & 6.3 & 5.9 \\
$\mathbf{4}$ & 7.4 & 5.1 & 7.0 & 6.5 & 5.8 \\
$\mathbf{5}$ & 2.5 & 1.9 & 2.3 & 2.7 & 2.1 \\
$\mathbf{6}$ & 8.4 & 6.3 & 7.2 & 7.3 & 6.3 \\
$\mathbf{7}$ & 6.8 & 5.0 & 7.0 & 7.1 & 6.9 \\
$\mathbf{8}$ & 6.8 & 5.2 & 6.0 & 6.5 & 5.6 \\
Doxorubicin & 0.07 & 0.2 & 0.03 & 0.3 & 0.2 \\
\hline
\end{tabular}

a) $\mathrm{IC}_{50}$ is defined as the concentration which resulted in a $50 \%$ decrease in cell number. b) The values represent the means of three independent experiments.

Table 3. NO Production and Cytotoxic Effects of $\mathbf{1}-\mathbf{8}$ in LPS-Induced RAW 264.7 Macrophage Cell

\begin{tabular}{ccc}
\hline \hline & \multicolumn{2}{c}{$\mathrm{IC}_{50}(\mu \mathrm{g} / \mathrm{ml})^{a)}$} \\
\cline { 2 - 3 } Compound & NO inhibition & Cytotoxicity \\
\hline $\mathbf{1}$ & $69.23^{b)}$ & $>100$ \\
$\mathbf{2}$ & 12.2 & 14.6 \\
$\mathbf{3}$ & 5.94 & 5.92 \\
$\mathbf{4}$ & 10.38 & 9.01 \\
$\mathbf{5}$ & 2.14 & 5.14 \\
$\mathbf{6}$ & 11.63 & 11.42 \\
$\mathbf{7}$ & 3.68 & 3.58 \\
$\mathbf{8}$ & 5.06 & 4.05
\end{tabular}

a) $\mathrm{IC}_{50}$ is defined as the concentration which resulted in a $50 \%$ decrease in nitrite accumulation and cell number. b) The values represent the means of three independent experiments.

of the sugars and the same sapogenin. This result indicates that the linkage of the second sugar, rhamnose, manifests more potent activity than glucose. The cytotoxic effects of 7 and $\mathbf{8}$ with additional glucose and xylose as the third sugar, respectively, were lower than $\mathbf{5}$, suggesting that the third sugar of $\mathbf{7}$ and $\mathbf{8}$ may inhibit the potency of kalopanaxsapnin A (5). Compound 5 was the most potent of the tested saponins.

The inhibitory effects of $\mathbf{1}-\mathbf{8}$ on the formation of NO in LPS-activated macrophages was determined by a nitrite assay. Kalopanaxsaponin A was found to have a potent inhibitory effect on the production of nitric oxide by LPS-activated macrophage 264.7 whereas others had NO inhibition $\mathrm{IC}_{50}$ values that were similar to their cytotoxic $\mathrm{IC}_{50}$ 's. 


\section{DISCUSSION}

During the isolation of the saponins and the cytotoxic activity tests, we found that oleanane-type triterpene glycosides are quite different from ursane-type triterpene glycosides in terms of their sugar linkages. ${ }^{18)}$ The former triterpene frequently attaches disaccharides or oligosaccharides to form saponins, whereas the latter hardly forms oligosaccharides, suggesting that the disaccharide in oleanane glycosides is important for the cytotoxicity, although it has exception in the case of retaining uronic acid. Sugars in these triterpenoids may determine the presence or absence of cytotoxicity and perhaps cytotoxic potency.

Our SRB assay results suggest that $\alpha$-L-rhamnopyranosyl $(1-2)-\alpha$-L-arabinopyranosyl in kalopanaxsaponin $\mathrm{A}$ is the most effective of the tested saponins, regardless of the sapogenin type. Additional sugars in compounds 7 and 8 did not enhance the cytotoxicity of kalopanaxsaponin A. The second sugar, rhamnose, contributed more to the cytotoxicity than glucose. In view of our results and those previously reported, it appears that only the axially attached second sugar of $4^{\prime}$ - $O$ - $\beta$-glucosyl $\delta$-hederin (=hederagenin 3- $O$-[ $\beta$-D-glucopyranosyl-( $1 \rightarrow 4)-\alpha$-L-arabinopyranoside]) does not play any significant role in cytotoxicity. The present study provides information as to why the saponins of oleanane glycosides contain disaccharides. Moreover, kalopanaxsaponin A with a non-cytotoxic $\delta$-hederin moiety has been found to have several biologic effects, e.g., antispasmodic, ${ }^{19)}$ antileishmanicidic $^{20)}$ and anti-proliferative activity. ${ }^{21)}$

One of the significant bioactivities of saponins is their anti-inflammatory effect. Although a number of saponins, as well as their prosapogenins or sapogenins, could be developed as anti-cancer agents from cytotoxicity, anti-inflammatory activity screening of the compounds, benefit could also be expected to follow inducible nitric oxide inhibition. NO has diverse physiological roles and also contributes to the immune defense against viruses, bacteria, and other parasites. However, excessive production of NO is associated with various diseases, including arthritis, diabetes, stroke, septic shock, autoimmune diseases, chronic inflammatory diseases, and atherosclerosis. ${ }^{22)}$ Only kalopanaxsaponin A was found to have an inhibitory effect on the nitric oxide produced in LPS-activated macrophage 264.7. Other compounds tested, which included saponins with other linkages or other kinds of second sugar, did not show such an effect since their cytotoxic $\mathrm{IC}_{50}$ 's were found to be lower or similar than those of NO inhibition, which indicates that NO inhibitory effects are due to cell death rather than to the inhibition of NO produc- tion. Therefore, we suggest that kalopanaxsaponin A is a predominant anti-inflammatory saponin that has the disaccharide structure of $\alpha$-L-rhamnopyranosyl (1-2)- $\alpha$-L-arabinopyranosyl.

Acknowledgements This research was supported by a grant (PF002104-07) from the Plant Diversity Research Center of 21st Century Frontier Research Program funded by the Korean Ministry of Science and Technology.

\section{REFERENCES}

1) "Pharmacognosy," 3rd ed., Dong Myung Sa, Seoul, 2001, p. 211.

2) Higuchi R., Kawasaki T., Chem. Pharm. Bull., 24, 1021-1032 (1976).

3) Ikuta A., Itokawa H., Phytochemistry, 27, 3809-3810 (1988).

4) Quetin-Leclercq J., Elias R., Balansard G., Bassleer R., Angenot L., Planta Med., 58, 279-281 (1992).

5) Lee K. T., Sohn I. C., Park H. J., Kim D. W., Jung G. O., Planta Med., 66, 329-332 (2000).

6) Park H. J., Kwon S. H., Lee J. H., Lee K. H., Miyamoto K., Lee K. T., Planta Med., 67, 118-121 (2001).

7) Mimaki Y., Kuroda M., Asano T., Sashida Y., J. Nat. Prod., 62, 12791283 (1999).

8) Lee K. T., Choi J. W., Jung W. T., Nam J. H., Jung H. J., Park H. J., J. Agric. Food Chem., 50, 4190-4193 (2002).

9) Kim D. H., Yu K. W., Bae E. A., Park H. J., Choi J. W., Biol. Pharm. Bull., 21, 360-365 (1998).

10) Kim D. H., Kim E. A., Han M. J., Park H. J., Choi J. W., Biol. Pharm. Bull., 25, 68-71 (2002).

11) Ahmad V. U., Rahman A. U., "Handbook of Natural Products Data," Vol. II, Elsevier, Amsterdam, 1994, pp. 111-112, 223-224.

12) Ahmad V. U., Anwer B., "Spectroscopic Data of Saponins," CRC Press, Florida, 2000.

13) Timbekova A. E., Isaev M. I., Abubakirov N. K., Adv. Exp. Med. Biol., 405, 171-182 (1996).

14) Kim D. Y., Lee I. S., Jung J. H., Lee C. O., Choi S. U., Psammaplin A., Anticancer Res., 19, 4085-4090 (1999).

15) Rubinstein L. V., Shoemaker R. H., Paull K. D., Simon R. M., Tosini S., Skehan P., Scudiero D. A., Monks A., Boyd M. R., J. Natl. Cancer Inst., 82, 1113-1118 (1990).

16) Green L. C., Wagner D. A., Glogowsky J., Skipper P. L., Wishnok J. S., Tannenbaum S. R., Anal. Biochem., 126, 131-138 (1982).

17) Girma M. W., Michael W., J. Agric. Food Chem., 49, 2327-2332 (2001).

18) Tapondjou L. A., Lonsti D., Sondengam B. L., Choudhary M. L., Park H. J., Choi J. W., Lee K. T., Arch. Pharm. Res., 25, 270-274 (2002).

19) Trute A., Gross J., Mutschler E., Nahrstedt A., Planta Med., 63, 125 129 (1996).

20) Majester-Savornin B., Elias R., Diaz-Lanza A. M., Balansard G., Gasquet M., Delmas F., Planta Med., 57, 260-262 (1991).

21) Danloy S., Quetin-Leclercq J., Coucke P., De Pauw-Gillet M. C., Elias R., Balansard G., Argenot L., Bassleer R., Planta Med., 60, 45-49 (1994).

22) Bredt D. S., Snyder S. H., Annu. Rev. Biochem., 63, 175-195 (1994). 